\title{
Leptin Inhibits Preproinsulin mRNA Expression Induced by Suppression of Cytokine Signalling 3 in Beta-Cells
}

\author{
Jiaqiang Zhou ${ }^{1 *}$, Jiahua $\mathrm{Wu}^{1}$, Fengqin Dong ${ }^{2}$, Zhe Zhang ${ }^{2}$, Fang $\mathrm{Wu}^{1}$ and Hong $\mathrm{Li}^{1}$ \\ ${ }^{1}$ Department of Endocrinology, Sir Run Run Shaw Hospital, Zhejiang University School of Medicine, Hangzhou, 310016, China \\ ${ }^{2}$ Department of Endocrinology, The First Affiliated Hospital, Zhejiang University School of Medicine, Hangzhou, 310003, China
}

${ }^{*}$ Corresponding author: Jiaqiang Zhou, Department of Endocrinology, Sir Run Run Shaw Hospital, Zhejiang University, School of Medicine, 3 East Qingchun Road, Hangzhou, 310016, Zhejiang, China; Tel: 0571 86006640; E-mail: zhoujq27@foxmail.com

Copyright: @ 2014 Zhou J, et al. This is an open-access article distributed under the terms of the Creative Commons Attribution License, which permits unrestricted use, distribution, and reproduction in any medium, provided the original author and source are credited.

\author{
Abstract \\ Aim: To study the role of crosstalk between SOCS3 and leptin on insulin expression in rat insulinoma (RIN-5AH) \\ cells that inducibly express SOCS3 mRNA.
}

Materials and Methods: SOCS3 and preproinsulin mRNA expression induced by $5 \mu \mathrm{M}$ ponasterone A, and the effects of leptin on SOCS3 and preproinsulin mRNA levels were detected by RT-PCR and quantitative PCR, respectively. The effects of SOCS3 on STAT3 phosphorylation were investigated by Western blot analysis.

Results: We discovered that SOCS3 regulates preproinsulin mRNA levels in a dose-dependent and timedependent manner. The insulin-suppressing effect of leptin appears to be mediated through reducing the suppressive effects of SOCS3 on STAT3 phosphorylation.

Conclusion: Our findings suggest that leptin inhibits preproinsulin mRNA expression induced by SOCS3 in RIN-5AH beta-cells.

Keywords: Leptin; Insulin; SOCS3; Beta-cells

\section{Introduction}

Obesity is a major cause of the increasing morbidity and mortality associated with diseases such as type- 2 diabetes and cardiovascular disease. Leptin and insulin, which are key hormones involved in the regulation of energy production and glucose homeostasis, play roles in the pathogenesis of type-2 diabetes. On binding to the long form of the leptin receptor (LRb), leptin induces STAT3 phosphorylation, which subsequently regulates the expression of certain genes [1]. Dysfunctional mutations in leptin or its receptor in rodents and humans result in severe obesity, insulin resistance, and endocrine dysfunction [2-4].

Suppressor of cytokine signaling (SOCS) proteins are key negative regulators of cytokine signaling that inhibit the JAK/STAT signal transduction pathway [5]. SOCS3 negatively regulates the expression of multiple hormones and cytokines including TNF- $\alpha$ and IL-6 [6,7]. SOCS3 has also been reported to affect the signaling of both leptin and insulin. SOCS3 does not alter the levels of the leptin receptor but binds to Tyr985 on the receptor to suppress STAT3 signaling $[8,9]$. Heterozygous SOCS3 knockout mice (SOCS3+/-) display higher leptin sensitivity than wild-type mice. In response to leptin administration, these mice lose weight and exhibit hypothalamic leptin receptor signaling [10]. SOCS3 has also been shown to regulate insulin signaling. SOCS3 binds to Tyr960 on the insulin receptor and prevents STAT5b activation in adipocytes [11]. Using an adipocyte model derived from fibroblasts of wild-type and SOCS3-deficient mouse embryos, Shi et al. investigated the role of endogenous SOCS3 in insulin signaling. SOCS3 deficiency leads to increased insulin- stimulated glucose uptake in adipocytes [12]. Shi et al. also established a transgenic mouse model in which SOCS3 was overexpressed in adipocytes. Overexpression of SOCS3 results in reduced glucose uptake and lipogenesis in adipocytes [13]. Thus, given its regulatory effects in both the leptin and insulin pathways, SOCS3 is likely to be a key node in the crosstalk between the leptin and insulin signaling cascades.

In this study, we investigated the role of crosstalk between SOCS3 and leptin in insulin expression. We discovered that SOCS3 regulates preproinsulin mRNA levels in a dose- and time-dependent manner. Leptin has been shown to suppress insulin expression by inhibiting the expression of SOCS3. Thus, these findings imply that SOCS3 plays a key role in mediating the interaction between the leptin and insulin pathways.

\section{Materials and methods}

\section{Antibodies and reagents}

Zeocin and ponasterone A were purchased from Invitrogen (Carlsbad, CA, USA). G418 was purchased from Calbiochem (Darmstadt, Germany). The anti-STAT3 and anti-pSTAT3 antibodies were both purchased from Upstate (Lake Placid, NY, USA). Leptin was purchased from R\&D Systems (Minneapolis, MN, USA). Taq DNA polymerase was purchased from Promega (Madison, WI, USA). TRIzol reagent was purchased from Sigma (St. Louis, MO, USA). Cell lysis buffer (RIPA) was purchased from Beyotime (Jiangsu, China). 
Citation: Zhou J, Wu J, Dong F, Zhang Z, Wu F, et al. (2014) Leptin Inhibits Preproinsulin mRNA Expression Induced by Suppression of Cytokine Signalling 3 in Beta-Cells. J Metabolic Synd 3: 153. doi:10.4172/2167-0943.1000153

Page 2 of 4

\section{Beta-cell-derived stable cell line}

RIN-5AH cells stably transfected with inducible SOCS3 (gift from Prof. Billestrup) [14] were cultured in RPMI-1640 medium supplemented with $10 \%$ heat-inactivated fetal calf serum, glutamax, $100 \mathrm{U} / \mathrm{ml}$ penicillin, $100 \mu \mathrm{g} / \mathrm{ml}$ streptomycin, $400 \mu \mathrm{g} / \mathrm{ml}$ zeocin, and $150 \mu \mathrm{g} / \mathrm{ml} \mathrm{G} 418$ at $37^{\circ} \mathrm{C}$ in a humidified atmosphere containing $5 \%$ $\mathrm{CO} 2$. The cells were tested for ponasterone A-induced SOCS3 expression by RT-PCR.

\section{Reverse-transcription PCR}

Cells were cultured in a 6-well plate to $80 \%$ confluence and then treated with $5 \mu \mathrm{M}$ ponasterone A for $48 \mathrm{~h}$. Total RNA was isolated with TRIzol reagent. SOCS3 mRNA was amplified by reversetranscription PCR. The $40 \mu \mathrm{l}$ DNA amplification reactions contains 4 $\mu \mathrm{l} 10 \mathrm{x}$ reaction buffer, $25 \mathrm{mM} \mathrm{MgCl} 2,10 \mathrm{mM}$ dNTP, 5 unit Taq DNA polymerase, $4 \mu \mathrm{lc}$ DNA and $0.5 \mathrm{ul}$ each of the primers. The reaction was denatured for $3 \mathrm{~min}$ at $94^{\circ} \mathrm{C}$ and subjected to 3-step amplification cycles with denaturation at $94^{\circ} \mathrm{C}$ for $15 \mathrm{sec}$, annealing at $57^{\circ} \mathrm{C}$ for 20 sec and extend at $60^{\circ} \mathrm{C}$ for $1 \mathrm{~min}$. To amplify GAPDH gene, PCR program was cycled for 35 times. To amplify SOCS3 gene, PCR program was cycled for 30 times. The primer sequences were: SOCS3 forward, 5'-GGGCCCCTTCCTTTTCTTTAC-3'; SOCS3 reverse, 5'GTCCAGGAACTCCCGAATG-3'; GAPDH forward, 5'GTCGGTGTGAACGGATTT-3'; GAPDH reverse, 5'ACTCCACGACGTACTCAGC-3'. PCR products were resolved on agarose gels, and bands were quantified using the BioSens Gel Imaging System.

\section{Quantitative PCR}

Cells were cultured in 6-well plates to $80 \%$ confluence and treated with $5 \mu \mathrm{M}$ ponasterone $\mathrm{A}$ and the indicated agents. Total RNA was isolated using the TRIzol reagent. The level of preproinsulinm RNA was quantified by real-time PCR. The GAPDH mRNA level was used as an internal control. Real-time PCR was performed using the ABI 7000 system (Applied Biosystems, Foster City, CA, USA) according to the manufacturer's protocol. The primer sequences were: preproinsulin forward, 5'-CAACATGGCCCTGTGGATGC-3'; preproinsulin reverse, 5'-TACAGAGCCTCCACCAGGTG-3'; preproinsulin probe, 5'-FAM-CCTGCTGGCCCTGCTCGTCCTCTTAMRA-3'; GAPDH forward, 5'-GACAGCCGCATCTTCTTG-3'; GAPDH reverse, 5'-GGCAACAATGTCCACTTTG-3'; GAPDH probe, 5'-FAM-CAGTGCCAGCCTCG-BHQ1-3'.

\section{Western blotting}

Cells were grown in $10-\mathrm{cm}$ dishes to $80 \%$ confluence and then cultured in the presence of $5 \mu \mathrm{M}$ ponasterone A for $46 \mathrm{~h}$. The cells were washed twice with Krebs-Ringer buffer $(140 \mathrm{mM} \mathrm{NaCl}, 3.6 \mathrm{mM}$ $\mathrm{KCl}, 0.5 \mathrm{mM} \mathrm{NaH} \mathrm{PO}_{4}, 0.5 \mathrm{mM} \mathrm{MgSO}, 1.5 \mathrm{mM} \mathrm{CaCl}_{2}, 10 \mathrm{mM}$ HEPES, $2 \mathrm{mM} \mathrm{NaHCO}_{3}$, and $0.1 \% \mathrm{BSA}$ [pH 7.4]) and incubated in the same buffer for $2 \mathrm{~h}$. The cells were then stimulated by treatment with $10 \mathrm{nM}$ leptin for $30 \mathrm{~min}$. To prepare protein extracts, cells were washed with cold PBS twice and lysed in RIPA. After centrifugation at $13,000 \mathrm{rpm}$ for $10 \mathrm{~min}$, the supernatants were collected. Protein concentration was measured using the BCA Protein Assay Kit from Pierce. Proteins were separated by electrophoresis in an 8\% PAGE gel. Bands were visualized using the Super Signal West Femto Maximum Sensitivity Substrate from Pierce and a Kodak X-ray film.

\section{Statistical analysis}

Data are presented as mean \pm SEM. Statistical differences between the various groups were determined using Student's t-test or ANOVA. P-values less than 0.05 were considered to indicate statistical significance.

\section{Results}

\section{Ponasterone A induces SOCS3 expression in RIN-5AH cells}

The RIN-5AH beta-cell line was used to establish cells that inducible express the SOCS3 protein [14]. To validate this inducible expression system, cells were incubated with various concentrations of ponasterone A, and the expression of SOCS3 mRNA was measured by RT-PCR as a function of time. As shown in Figure 1, the SOCS3 induction was dose- and time- dependent. The maximum expression of SOCS 3 mRNA was observed in the presence of $5 \mu \mathrm{M}$ ponasteroneA after $24 \mathrm{~h}$ of stimulation. Under these conditions, the levels of SOCS3 mRNA were 4.4-fold higher than those in untreated cells $(\mathrm{p}<0.05)$.

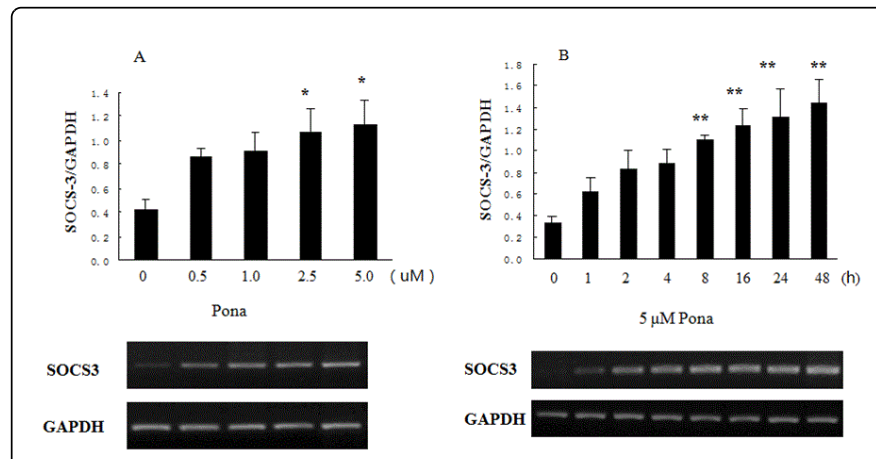

Figure 1: Dose-dependent and time-dependent SOCS3 expression induced by ponasterone A. (A) SOCS3 expression was induced in RIN-5AH cells by treatment with the indicated concentrations of ponasterone A for $48 \mathrm{~h}$. The levels of SOCS3 mRNA were determined by RT-PCR. (B) SOCS3 expression was induced in RIN-5AH cells by treatment with $5 \mu \mathrm{M}$ ponasterone A. SOCS3 levels were determined by RT-PCR and plotted as a function of time. GAPDH was used as an internal control. $\mathrm{n}=4$. ${ }^{*}, \mathrm{P}<0.05$; **, $\mathrm{P}<0.01$ compared with the control group

\section{SOCS3 expression enhances preproinsulin mRNA levels}

Ponasterone A treatment also enhanced preproinsulin expression in the stable cell line. As shown in Figure 2, the expression of preproinsulin mRNA was dose- and time-dependent. After $8 \mathrm{~h}$ of treatment with $5 \mu \mathrm{M}$ ponasterone $\mathrm{A}$, we observed a significant increase in the preproinsulin mRNA levels, and the maximum effect was observed between 24 and $48 \mathrm{~h}(\mathrm{p}<0.05)$. The maximum preproinsulin level was 4.4 -fold higher than that of untreated cells $(p<0.05)$. The expression of preproinsulin was strongly correlated with the expression of SOCS3. 


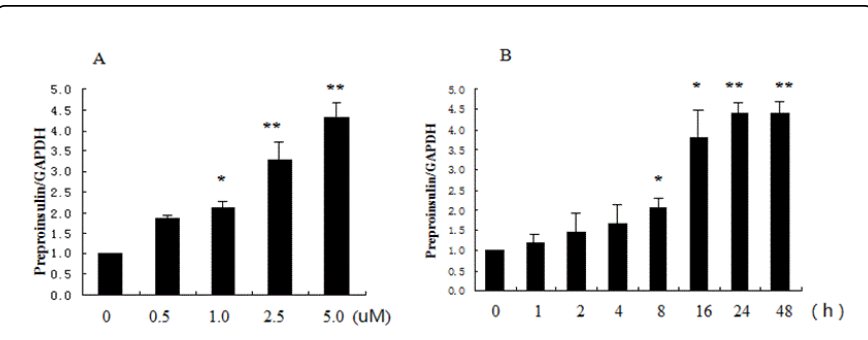

Figure 2: Ponasterone A treatment increased preproinsulin mRNA levels in RIN-5AH cells that express SOCS3. (A) Preproinsulin expression was induced in RIN-5AH cells by treatment with the indicated concentrations of ponasterone A for $48 \mathrm{~h}$. The levels of preproinsulin mRNA were analyzed by real-time PCR. (B) Preproinsulin expression was induced in RIN-5AH cells by treatment with $5 \mu \mathrm{M}$ ponasterone A. Cells were collected at the indicated time points, and the levels of preproinsulin mRNA were determined by real-time PCR. GAPDH was used as an internal control. $\mathrm{N}=3$. ${ }^{*}, \mathrm{P}<0.05 ;{ }^{* *}, \mathrm{P}<0.01$ compared with the control group

\section{Leptin treatment inhibits the SOCS3 and preproinsulin mRNA levels}

SOCS3 has been proposed to be a mediator of leptin resistance $[15,16]$. To further study the correlations between SOCS3, leptin, and insulin levels, the stable cell line was stimulated with ponasterone A and leptin. The SOCS3 and preproinsulin mRNA levels were measured using RT-PCR or quantitative PCR. As shown in Figure 3, in the absence of ponasterone $\mathrm{A}$, under which condition SOCS3 induction was not triggered, addition of leptin did not change the preproinsulin levels.

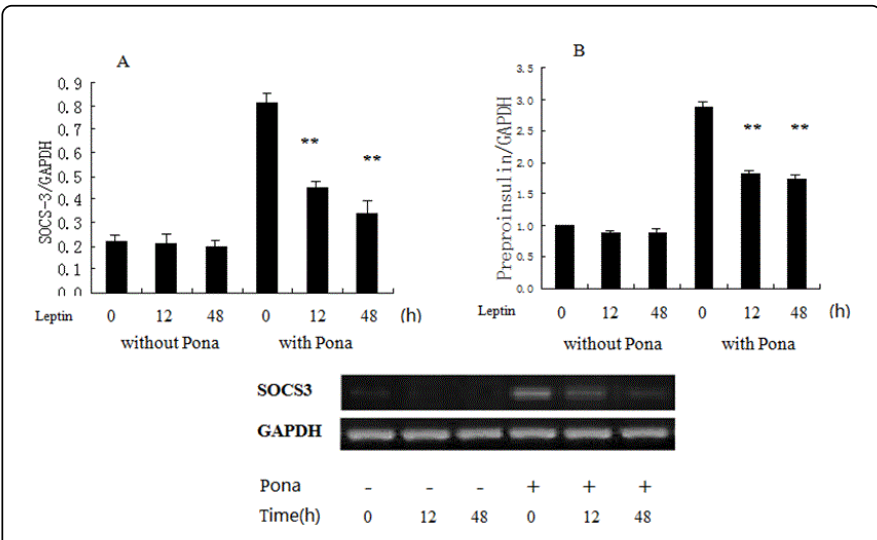

Figure 3: Leptin suppresses SOCS3 expression and decreases preproinsulin mRNA levels. SOCS3 expression was induced in RIN-5AH cells by treatment with $5 \mu \mathrm{M}$ ponasterone A for $48 \mathrm{~h}$. Cells were then treated with $10 \mathrm{nM}$ leptin for 12 or $48 \mathrm{~h}$. The levels of (A) SOCS3 and (B) preproinsulin mRNAs were determined by RT-PCR or quantitative real-time PCR. GAPDH was used as an internal control. $\mathrm{n}=3 .{ }^{* *}, \mathrm{P}<0.01$ compared with the control group

However, in the presence of ponasterone A, treatment with leptin suppressed SOCS3 as well as preproinsulin mRNA expression. The suppressive effect was time-dependent. After $10 \mu \mathrm{M}$ leptin treatment for $48 \mathrm{~h}$, the SOCS3 mRNA level decreased by $58 \%$ and the preproinsulin mRNA level decreased by $40 \%$ relative to the levels in cells not treated with leptin $(\mathrm{p}<0.01)$. These data suggest that the suppressive effects of leptin on insulin are related to SOCS3.

\section{Leptin reduces the suppressive effects of SOCS3 on STAT3 phosphorylation}

SOCS3 has been reported to inhibit STAT3 phosphorylation [17]. As shown in Figure 4, ponasteroneA treatment of cells to induce SOCS3 expression decreased STAT3 phosphorylation. When cells induced to express SOCS3 were also treated with leptin, the STAT3 phosphorylation levels were similar to the levels in cells not treated with ponasterone $\mathrm{A}$.

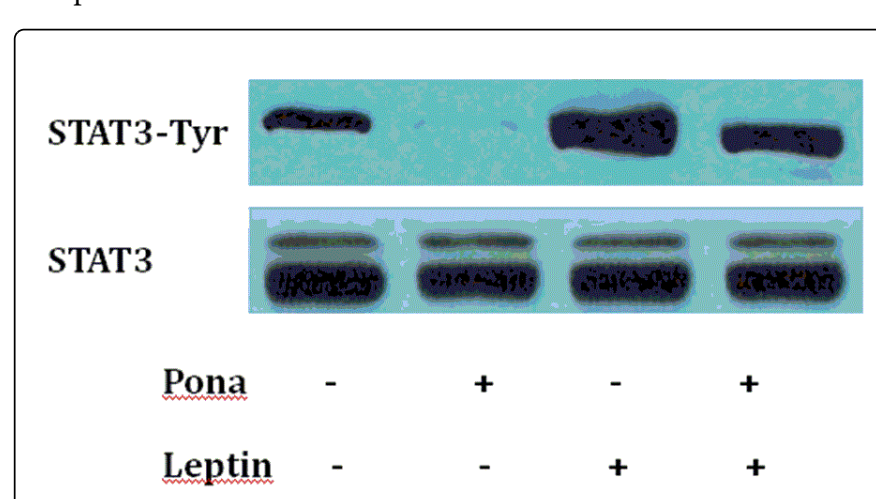

Figure 4: Leptin reduces the suppressive effect of SOCS3 on STAT3 phosphorylation. RIN-5AH cells were cultured in the presence or absence of $5 \mu \mathrm{M}$ ponasterone A for $48 \mathrm{~h}$ and then were stimulated with $10 \mathrm{nM}$ leptin for $30 \mathrm{~min}$ or left unstimulated. Cell lysates were separated by SDS-PAGE and analyzed for STAT3 and phosphorylated STAT3 (STAT3-Tyr). The image shown is representative of three independent experiments

\section{Discussion}

In this study, we used an insulin-producing beta-cell line to create an ecdysone-inducible system to mimic the interactions among leptin, SOCS3, and insulin. After incubation with ponasteroneA, exogenous SOCS3 was expressed in the beta-cell line in a dose- and timedependent manner. The effect of ponasteroneA treatment on mRNA transcription and protein expression in these cells is well established [14]. Using this system, we investigated the effects of SOCS3 expression and leptin treatment on insulin expression. We found that SOCS3 affected the preproinsulin mRNA expression, and that treatment with leptin suppressed SOCS3 mRNA expression and decreased the preproinsulin mRNA levels.

STAT protein, which is key mediator in leptin signal transduction, is also suppressed by SOCS3 [17]. STATs have mainly been shown to transcriptionally enhance gene expression. However, Seufert et al. found that leptin increases the binding of STAT5b to the upstream sequences of the rat preproinsulin 1 promoter and inhibits insulin biosynthesis via transcriptional repression [18]. Furthermore, fructose increased SOCS3 expression, decreased STAT3 phosphorylation, increased Pdxl and insulin gene expression, and induced hyperinsulinemia both in rats and in INS-1 cells [19]. Quercetin treatment suppressed the increased SOCS3 level, elevated the reduced STAT3 level, and improved leptin signalling, thereby protecting beta- 
Citation: Zhou J, Wu J, Dong F, Zhang Z, Wu F, et al. (2014) Leptin Inhibits Preproinsulin mRNA Expression Induced by Suppression of Cytokine Signalling 3 in Beta-Cells. J Metabolic Synd 3: 153. doi:10.4172/2167-0943.1000153

Page 4 of 4

cell function under high-fructose conditions [19]. In accordance with the previous studies, in our study, over expression of SOCS3 inhibited STAT3 phosphorylation and then increased preproinsulin mRNA expression. However, leptin decreased the SOCS3-induced preproinsulin expression through enhancement of STAT3 phosphorylation. As previously reported, SOCS3 expression reverses the stimulatory effect of growth hormones on pancreatic beta-cell proliferation and insulin secretion. Furthermore, SOCS3 protects pancreatic beta-cells from IL- $1 \beta$ - and IFN- $\gamma$-mediated cytotoxicity but does not alter insulin levels $[14,20]$. Based on these results, we propose that SOCS3 plays multiple roles in pancreatic beta-cells and that it might be an important mediator of crosstalk between the insulin and leptin pathways. As the RIN-5AH $\beta$-cell line did not induce a significant amount of insulin release with glucose, we could not investigate the effect of SOCS3 on glucose-stimulated insulin release. Further investigations that use islets from SOCS3 transgenic mice will be conducted to investigate the effect of SOCS3 on preproinsulin mRNA expression and glucose-stimulated insulin release.

\section{Funding}

This work was supported by a grant from the National Natural Science Foundation of China (No. 30400221).

\section{References}

1. Hübschle T, Thom E, Watson A, Roth J, Klaus S, et al. (2001) Leptininduced nuclear translocation of STAT3 immunoreactivity in hypothalamic nuclei involved in body weight regulation. J Neurosci 21: 2413-2424.

2. Fischer-Posovszky P, von Schnurbein J, Moepps B, Lahr G, Strauss G, et al. (2010) A new missense mutation in the leptin gene causes mild obesity and hypogonadism without affecting $\mathrm{T}$ cell responsiveness. J Clin Endocrinol Metab 95: 2836-2840.

3. Mantzoros CS (1999) The role of leptin in human obesity and disease: a review of current evidence. Ann Intern Med 130: 671-680.

4. Cheung WW, Mao P (2012) Recent advances in obesity: genetics and beyond. ISRN Endocrinol 2012: 536905.

5. Murray PJ (2007) The JAK-STAT signaling pathway: input and output integration. J Immunol 178: 2623-2629.

6. Bruun C, Heding PE, Rønn SG, Frobøse H, Rhodes CJ, et al. (2009) Suppressor of cytokine signalling-3 inhibits Tumor necrosis factor-alpha induced apoptosis and signalling in beta cells. Mol Cell Endocrinol 311: 32-38.
7. Johnston JA (2004) Are SOCS suppressors, regulators, and degraders? J Leukoc Biol 75: 743-748.

8. Bjorbak C, Lavery HJ, Bates SH, Olson RK, Davis SM, et al. (2000) SOCS3 mediates feedback inhibition of the leptin receptor via Tyr985. J Biol Chem 275: 40649-40657.

9. Myers MG Jr (2004) Leptin receptor signaling and the regulation of mammalian physiology. Recent Prog Horm Res 59: 287-304.

10. Morton GJ, Schwartz MW (2011) Leptin and the central nervous system control of glucose metabolism. Physiol Rev 91: 389-411.

11. Emanuelli B, Peraldi P, Filloux C, Sawka-Verhelle D, Hilton D, et al. (2000) SOCS-3 is an insulin-induced negative regulator of insulin signaling. J Biol Chem 275: 15985-15991.

12. Shi H, Tzameli I, Bjørbaek C, Flier JS (2004) Suppressor of cytokine signaling 3 is a physiological regulator of adipocyte insulin signaling. J Biol Chem 279: 34733-34740.

13. Shi H, Cave B, Inouye K, Bjørbaek C, Flier JS (2006) Overexpression of suppressor of cytokine signaling 3 in adipose tissue causes local but not systemic insulin resistance. Diabetes 55: 699-707.

14. Rønn SG, Hansen JA, Lindberg K, Karlsen AE, Billestrup N (2002) The effect of suppressor of cytokine signaling 3 on GH signaling in beta-cells. Mol Endocrinol 16: 2124-2134.

15. Bjørbaek C, Elmquist JK, Frantz JD, Shoelson SE, Flier JS (1998) Identification of SOCS-3 as a potential mediator of central leptin resistance. Mol Cell 1: 619-625.

16. Król E, Speakman JR (2007) Regulation of body mass and adiposity in the field vole, Microtusagrestis: a model of leptin resistance. J Endocrinol 192: 271-278.

17. Dominguez E, Mauborgne A, Mallet J, Desclaux M, Pohl M (2010) SOCS3-mediated blockade of JAK/STAT3 signaling pathway reveals its major contribution to spinal cord neuroinflammation and mechanical allodynia after peripheral nerve injury. J Neurosci 30: 5754-5766.

18. Seufert J, Kieffer TJ, Habener JF (1999) Leptin inhibits insulin gene transcription and reverses hyperinsulinemia in leptin-deficient $\mathrm{ob} / \mathrm{ob}$ mice. Proc Natl Acad Sci U S A 96: 674-679.

19. Li JM, Wang W, Fan CY, Wang MX, Zhang X, et al. (2013) Quercetin Preserves $\beta$-Cell Mass and Function in Fructose-Induced Hyperinsulinemia through Modulating Pancreatic Akt/FoxO1 Activation. Evid Based Complement Alternat Med 2013: 303902.

20. Karlsen AE, Rønn SG, Lindberg K, Johannesen J, Galsgaard ED, et al. (2001) Suppressor of cytokine signaling 3 (SOCS-3) protects beta -cells against interleukin-1beta - and interferon-gamma -mediated toxicity. Proc Natl Acad Sci U S A 98: 12191-12196. 